\title{
Diagnosis Approach of Optic Neuritis
}

Pérez-Bartolomé Francisco ${ }^{1 *}$, García- Vasco Lorena ${ }^{2}$, Ventura- Abreu Nestor ${ }^{1}$, Arcos-Villegas Gabriel ${ }^{1}$, Santos-Bueso Enrique ${ }^{1}$, SáenzFrancés Federico', García-Feijoó Julián', Muñoz-Negrete Francisco ${ }^{3}$ and Rebolleda-Fernández Gema ${ }^{3}$

${ }^{1}$ Department of Ophthalmology, Hospital Clínico San Carlos, Universidad Complutense de Madrid, Spain

${ }^{2}$ Department of Neurology, Hospital 12 de Octubre, Universidad Complutense de Madrid, Spain

${ }^{3}$ Department of Ophthalmology, Hospital Ramón y Cajal, Universdidad Alcalá de Henares, Madrid, Spain

\begin{abstract}
The approach of the etiology of an optic neuropathy can be difficult for both ophthalmologists and neurologists, because neither the appearance of the optic disc, the perimetry, or the findings in Optical Coherence Tomography (OCT) or Magnetic Resonance Imaging (MRI) are specific. Clinical features common to optic neuropathies are vision loss, visual fields scotomas and dyschromatopsia. Pain is a variable feature that, when is present, suggest an inflammatory disorder. Relative afferent pupilary defect is a required clinical finding for the diagnosis of unilateral optic neuropathy. The term "Typical optic neuritis" (ON) has been widely used to design a unilateral ON that presents in a young patient with an acute or subacute presentation, with pain worsened with eye movements and generally good prognosis. In this scenario, idiopathic or Multiple Sclerosis (MS) are the most likely etiologies. Therefore, in these cases, brain MRI with gadolinium contrast should be performed in order to establish the risk of conversion to MS. OCT is a useful test to evidence the retinal nerve fiber layer and ganglion cell-inner plexiform layer changes. Any modification of the mentioned clinical pattern should be consider "atypical" and further investigation is necessary in order to discard other possibilities such as ischemic, autoimmune, compressive- infiltrative, hereditary, toxic, nutritional deficiency, posttraumatic, postradiotherapy or intracraneal hypertension. Therefore, we must follow a rational algorism from the most common cause to the most unlikely in each case, with a well-defined previous distinction of the typical and atypical features, because both the early diagnosis and treatment are overriding in the second ones.
\end{abstract}

Keywords: Optic neuritis; Multiple sclerosis; Ischemic optic neuropathy; Neuromyelitis optica (NMO); Chronic relapsing inflammatory optic neuritis (CRION)

\section{Introduction}

The optic nerve is confirmed by one million axons that derives from the retinal ganglion cells and constitutes an extension of the central nervous system (CNS). We usually refer to the optic nerve as the tract that extends from the eye to the optic chiasm. It has four anatomic portions well defined: intraocular or optic disc, intraorbital, intracanalicular and intracranial [1]. The optic disc is the only structure of the entire tract that has not myelin. One classic classification of optic neuritis has been anterior (or papilitis) and posterior (retrobulbar). The first one designs an inflammation of the optic disc and can be seen in the fundus examination as a peripapillary edema; the second one designs an inflammation in any portion between the eye and the optic chiasm and can be only seen in neuroimaging test. It was classically described as the disease in which "neither the patient nor the physician see anything". Anastomosing arterioles supplied by posterior ciliary arterioles, pial arteriole plexus, and choroid supplies the blood flow of the optic disc. Arteriosclerosis or arteritis of these vessels can lead to cause hypoperfusion of the optic nerve head and, subsequently, an anterior ischemic optic neuropathy (AION). The intraorbital segment receives blood from perforating branches of the ophthalmic artery. The intracanalicular and intracraneal portions are supplied by pial branches of the ophthalmic, internal carotid, anterior cerebral, and anterior communicating arteries [2].

Clinical features of an optic nerve lesion usually produce monocular vision loss. Pain is a variable feature that, when is present, suggest an inflammatory disorder. Nevertheless, some ischemic lesions can cause pain as well $[3,4]$. Other common features includes relative afferent pupilary defect (RAPD) (if the lesion is unilateral or asymmetric), central vision loss on visual field testing and dyschromatopsia [5]. Swinging flashlight test evidence the RAPD and may suppose the most valuable test in the clinical examination (Figure 1). It is found in most cases and, when not present, usually signifies that there is bilateral involvement or a previous damage, sometimes subclinical, of the fellow pregenicular afferent pathway. It presence is a required clinical feature for the diagnosis of unilateral optic neuropathy.

Worldwide, the principal cause of optic neuropathy is glaucoma. Briefly, we will summarize the main differential signs in a fundus examination between glaucomatous damage of the optic nerve head and a non- glaucomatous optic neuropathy (NGON). In glaucomatous eyes, neurorretinal ring appears to have a good healthy color but markedly thin, usually at superior and inferior, showing a focal enlargement of the cup. Other characteristic signs are asymmetry of cupping between patient eyes, paripapillary atrophy and disc hemorrhages without swelling. The principal funduscopic signs in NGON are the neurorretinal ring's pallor, especially in temporal (showing a horizontal enlargement of the cup) or an optic nerve head swelling (if anterior portion is affected) in the acute phase (Figure 2). Therefore, acquired enlargement of the cup does not always suggest glaucoma. Arteritic anterior ischemic optic neuropathy seen in giant cell arteritis (GCA-AAION) causes an enlargement of the cup in most of the patients affected [6]. As glaucoma is a bilateral disease, these patients do not usually present a RAPD. Known risk factors are higher

*Corresponding author: Francisco Pérez Bartolomé, Department of Ophthalmology. Hospital Clínico San Carlos, Prof. Martin Lagos Av, S/N. 28040 Madrid. Spain, Tel: + 34 913303000; Fax number: + 34 913303182; E-mail: Franciscoperezbartolome@gmail.com

Received November 13, 2015; Accepted December 28, 2015; Published December 30, 2015

Citation: Pérez Bartolomé F, García Vasco L, Abreu Ventura N, Arcos Villegas G, Santos Bueso E, et al. (2015) Diagnosis Approach of Optic Neuritis. J Neurol Neurophysiol 6: 345. doi:10.4172/2155-9562.1000345

Copyright: (C) 2015 Francisco PB, et al. This is an open-access article distributed under the terms of the Creative Commons Attribution License, which permits unrestricted use, distribution, and reproduction in any medium, provided the original author and source are credited. 
Citation: Pérez Bartolomé F, García Vasco L, Abreu Ventura N, Arcos Villegas G, Santos Bueso E, et al. (2015) Diagnosis Approach of Optic Neuritis. J Neurol Neurophysiol 6: 345. doi:10.4172/2155-9562.1000345
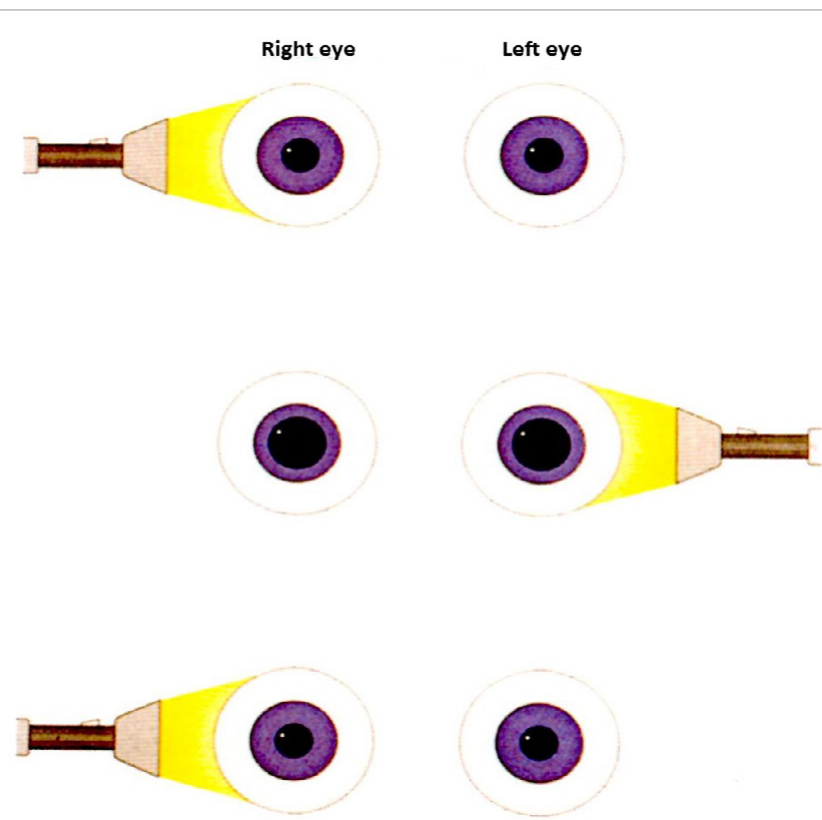

Figure 1: Swinging flashlight test showing a RAPD of the left eye. When the right eye is illuminated, light reflex appears in both eyes (direct and consensual); but, when the left eye is illuminated, neither of them response. This discloses a defect in the left pregenicular visual afferent pathway. Courtesy of Spanish Society of Ophthalmology. intraocular hypertension, steroids treatment, age and familiar history of the disease [7].

The approach of the etiology of NGON can be difficult for both ophthalmologists and neurologists, because neither the appearance of the optic disc, the perimetry, nor the findings in Optical Coherence Tomography (OCT) or Magnetic Resonance Imaging (MRI) are specific.

Mainly, there are nine big groups that summarize the etiology of a NGON: Inflammatory- optic neuritis (ON), ischemic, compressiveinfiltrative, hereditary, toxic, nutritional deficiency, post- traumatic, post- radiotherapy, or associated with intracraneal hypertension ( $\mathrm{ICH}$ ) (Table 1). ON is the most common cause of optic nerve disease in younger adults while ischemic optic neuropathy is the most common etiology in elderly patients [8].

This variety of possibilities does not allow us to perform the same test to all the patients who have been clinically diagnosed of an optic neuropathy. We must follow a rational algorism from the most common cause to the most unlikely in each case, with a previous well defined clinical diagnosis [9].

It is essential to know the way of onset and progression of the symptoms, the age of the patient, the presence or not of peripapillary edema, if it is a unilateral o bilateral disorder, personal history (trauma, neoplasia, drugs, etc.) and family history.

Toxic and nutritional deficiency optic neuropathies are usually

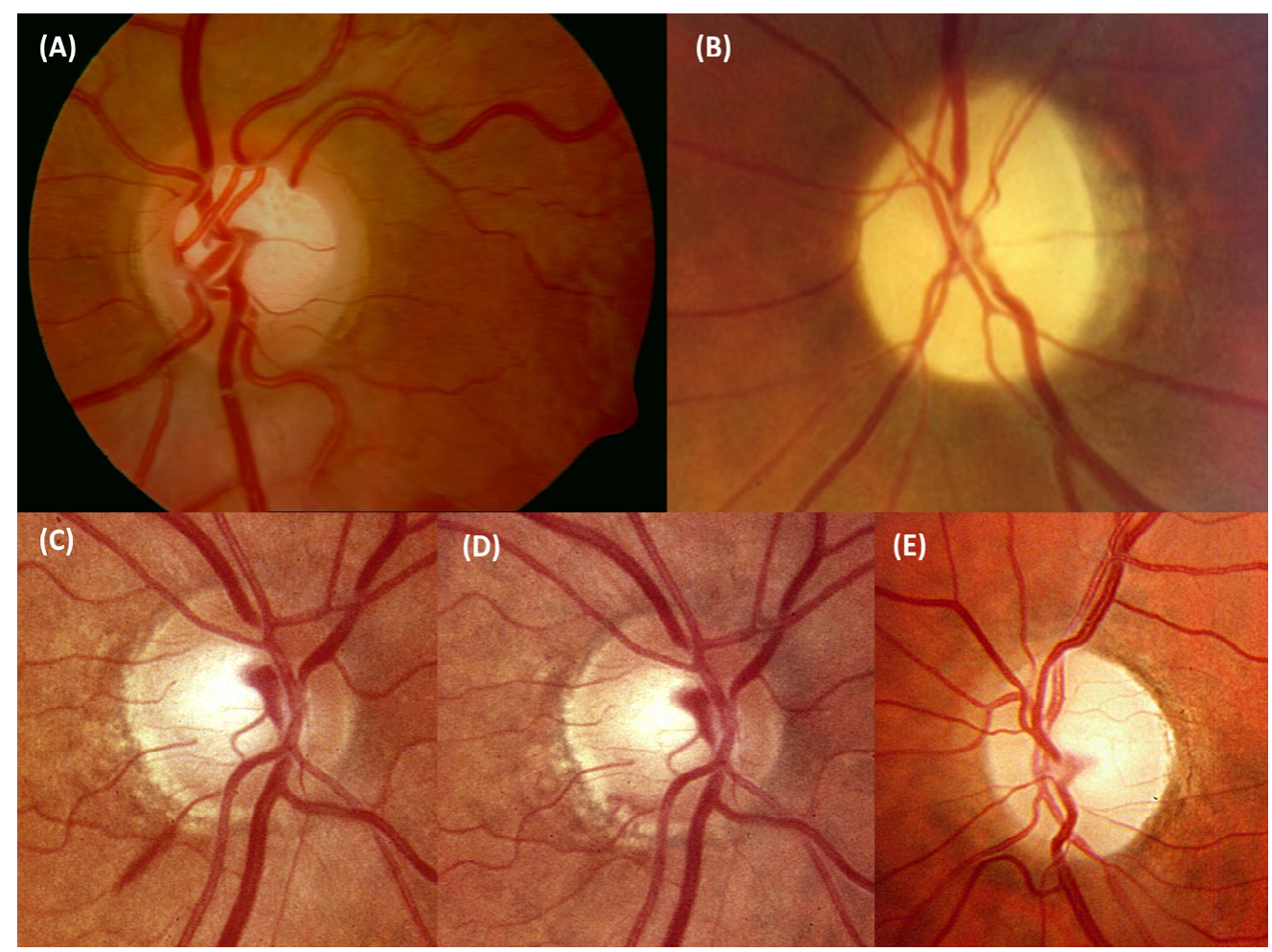

Figure 2: Differences between glaucomatous optic neuropathy and NGON. A. Glaucomatous optic neuropathy: Neuroretinal ring has a good healthy color but appears markedly thin, especially in superior. Enlargement of the cup is obvious. Parapapillary atrophy is shown in the nasal and temporal borders. This is a classically sign of glaucomatous optic disc, but it can also be seen in elderly patients. We also can see the vessels displaced to the nasal side and a notch in the inferior border. B. NGON: Neuroretinal ring has a pronounced pallor, showing a whole atrophy of the optic disc. This picture corresponds to a past NAION. C, D. Evolution of a disc hemorrhage in the inferior border in a glaucomatous disc. Usually disappears in 2- 6 months, and means progression of the optic nerve head damage. E. Optic atrophy in a NGON with superior and temporal pallor of neuroretinal ring. Courtesy of Spanish Society of Ophthalmology. 
Citation: Pérez Bartolomé F, García Vasco L, Abreu Ventura N, Arcos Villegas G, Santos Bueso E, et al. (2015) Diagnosis Approach of Optic Neuritis. J Neurol Neurophysiol 6: 345. doi:10.4172/2155-9562.1000345

\begin{tabular}{|c|c|c|c|c|}
\hline Ethiology & Unilateral or bilateral & Onset & Optic nerve head & Differential features \\
\hline $\begin{array}{l}\text { Inflammatory } \\
\text { neuropathy }(\mathrm{ON})\end{array}$ & $\begin{array}{l}\text { Unilateral (young adults) } \\
\text { Bilateral (children*, NMO*) }\end{array}$ & $\begin{array}{l}\text { Acute or } \\
\text { subacute }\end{array}$ & $\begin{array}{l}\text { Edema (one third of typical ON in } \\
\text { young adults); children* } \\
\text { Normal (two thirds of typical ON) }\end{array}$ & $\begin{array}{l}\text { Young femails*; moderate vision loss, spontaneosly recovering, } \\
\text { painfull with eye movements\#; central scotoma*; hyperintensity } \\
\text { and enhancement of the optic nerve in MRI }\end{array}$ \\
\hline NMO & $\begin{array}{l}\text { Bilateral*; sequential to the } \\
\text { fellow eye }\end{array}$ & $\begin{array}{l}\text { Acute or } \\
\text { subacute }\end{array}$ & $\begin{array}{l}\text { Diffuse edema without } \\
\text { hemorrhages }^{*}\end{array}$ & $\begin{array}{l}\text { Severe vision loss }{ }^{*} \text {; painfull eye }{ }^{*} \text {, unresponsive to steroids; TM; } \\
\text { AQP4 positive }^{*} \text {, normal brain MRI }\end{array}$ \\
\hline CRION & Unilateral & $\begin{array}{l}\text { Acute or } \\
\text { subacute }\end{array}$ & $\begin{array}{l}\text { Diffuse edema without } \\
\text { hemorrhages* }^{*}\end{array}$ & $\begin{array}{l}\text { Responsive to steroids but relapsing course; normal brain and } \\
\text { spinal MRI; AQP4 negative*; autoinmmune laboratory test } \\
\text { negative* }^{*}\end{array}$ \\
\hline AAION & $\begin{array}{l}\text { Unilateral; rapidly sequential } \\
\text { to the fellow eye without } \\
\text { steroid treatment }\end{array}$ & Acute & $\begin{array}{l}\text { Edema, RNFL hemorrhage; } \\
\text { chronic phase: pallor with } \\
\text { enlargement of the cup }\end{array}$ & $\begin{array}{l}\text { Elderly patients (>65 years old*), severe vision loss }{ }^{*} \text {, painfull } \\
\text { eye*, prodromic and systemic symptoms*; ESR and RCP } \\
\text { elevated }\end{array}$ \\
\hline NAION & $\begin{array}{l}\text { Unilateral; fellow eye often } \\
\text { show the "disc at risk" }\end{array}$ & Acute & $\begin{array}{l}\text { Sectorial edema*, RNFL } \\
\text { hemorrhage*, peripapillary } \\
\text { telangiectasia*, vessels } \\
\text { attenuation*; chronic phase: pallor }\end{array}$ & $\begin{array}{l}\text { Elderly patients ( }>50 \text { years old), cardiovascular risk factors } \\
\text { (arterial hypertension, diabetes, dyslipemia), obstructive sleep } \\
\text { apnea, altitudinal escotoma*, morning presentation* }\end{array}$ \\
\hline Compresive & Unilateral or bilateral & $\begin{array}{l}\text { Acute; subacute; } \\
\text { chronic }\end{array}$ & Normal; pallor; edema & Imaging test (CT, MRI); cancer history; unresponsive to steroids* \\
\hline Infiltrative & Unilateral or bilateral & $\begin{array}{l}\text { Acute; subacute; } \\
\text { chronic }^{*}\end{array}$ & Normal; pallor; edema & $\begin{array}{l}\text { Imaging test (CT, MRI); LP; cancer history*, unresponsive to } \\
\text { steroids*; systemic illness }^{*}\end{array}$ \\
\hline Sarcoidosis & Unilateral or bilateral & $\begin{array}{l}\text { Acute; subacute; } \\
\text { chronic }\end{array}$ & Normal; pallor; edema & $\begin{array}{l}\text { Young afroamerican females; systemic symptoms (cough, } \\
\text { erythema nodosum); optic neuropathy can result from ON, } \\
\text { granuloma (infiltrative), posterior uveítis or ICH }\end{array}$ \\
\hline Paraneoplasic & Bilateral* $^{*}$ & $\begin{array}{l}\text { Acute; subacute; } \\
\text { chronic }\end{array}$ & Normal; pallor; edema & Known/ prior cancer; positive anti-CRMP-5 IgG \\
\hline SLE; Vasculitis & Unilateral or bilateral & $\begin{array}{l}\text { Acute; subacute; } \\
\text { chronic }\end{array}$ & Normal $^{*}$; pallor; edema* & $\begin{array}{l}\text { Systemic features (respiratory symptoms, joint pain, dry mouth/ } \\
\text { dry eyes, skin lesions); positive biopsy; positive autoinmune } \\
\text { laboratoy tests }\end{array}$ \\
\hline Autoinmmune & Unilateral or bilateral & $\begin{array}{l}\text { Acute; subacute; } \\
\text { chronic }\end{array}$ & Normal $^{*}$; pallor; edema* & $\begin{array}{l}\text { Autoinmmune laboratoy test positive but unspecific (ANA, RF } \\
\text { etc) } \\
\text { Normal brain and spinal MRI; cutaneus biopsy compatible with } \\
\text { colagenous disease or vasculitis }\end{array}$ \\
\hline Infectious & Unilateral or bilateral & $\begin{array}{l}\text { Acute*; } \\
\text { subacute; } \\
\text { chronic }\end{array}$ & Normal $^{*}$; pallor; edema* & $\begin{array}{l}\text { Sexual exposure (syphilis, VIH); thick exposure (Lyme } \\
\text { disease); Cat/Kitten exposure, macular exudates (Bartonella); } \\
\text { inmmunosuppression }\end{array}$ \\
\hline Hereditary & $\begin{array}{l}\text { Bilateral (Leber: unilateral or } \\
\text { rapidly sequential) }\end{array}$ & $\begin{array}{l}\text { Chronic* } \\
\text { (Leber: acute or } \\
\text { subacute) }\end{array}$ & $\begin{array}{l}\text { Pallor (Leber: pseudoedema, } \\
\text { telangiectasias) }\end{array}$ & $\begin{array}{l}\text { Familiary history; central scotoma (Leber: young males, specific } \\
\text { mutations) }\end{array}$ \\
\hline Nutritional/ toxic & Bilateral & $\begin{array}{l}\text { Chronic } \\
\text { (metanol: acute } \\
\text { or subacute) }\end{array}$ & Normal; pallor (metanol: edema) & Toxic exposure; B12 vitamin deficit; central scotoma \\
\hline Traumatic & Unilateral or bilateral & Acute & $\begin{array}{l}\text { Normal; edema; optic nerve } \\
\text { avulsion }\end{array}$ & History of head trauma \\
\hline $\mathrm{ICH}$ & $\begin{array}{l}\text { Bilateral (unilateral: Foster } \\
\text { Kennedy syndrome) }\end{array}$ & Chronic & Edema & ICP increased; idiopathic ICH (young females, weight gain) \\
\hline
\end{tabular}

ON: Optic Neuritis; * Most Common; NMO: Neuromyelitis Optica; \#: Typical ON; AAION: Arteritic Ischemic Optic Neuropathy; RNFL: Retinal Nerve Fiber Layer; ESR: Erythrocyte Sedimentation Rate; RCP: Reactive C Protein; NAION: Non Arteritic Ischemic Optic Neuropathy; CT: Computed Tomography; MRI: Magnetic Resonance Imaging; TM: Transverse Mielitis; AQP4 Igg: Aquoporine 4 Inmmunoglobuline G; CRION: Chronic Relapsing Inflammatory Optic Neuritis; LP: Lumbar Puncture; ICH: Intracraneal Hypertension; Anti- CRMP-5 Igg: Antibodies Against Collapsing Response-Mediator Protein-5; SLE: Systemic Lupus Erythematosus; ICP: Intracraneal Presssure

Table 1: Common features of optic neuropathies.

presented as a bilateral disease. They must be discarded in patients with bilateral optic pallor and vision loss. The main treatment consists in withdrawing the toxic agent (methanol, ethanol, etc.) and vitamins supplementation, but a lot more treatments are actually being investigated [10]. In a peripapillary edema without or minimal vision loss, we must suspect ICH. Hence, the treatment in this scenario would be the cause of ICH.

Hereditary, post-traumatic and post-radiotherapy optic neuropathy has clear personal records. Nonetheless, some optic neuropathies considered hereditary, such as Leber's hereditary optic neuropathy (LHON), can onset without clear family records [10]. Nowadays, there is not an effective treatment for LHON [11]. Post- radiotherapy usually occurs several months after radiation of skull base tumors. Although rare, visual prognosis is usually poor.
ON must be suspected in a young adult with acute loss of vision; if, however, it occurs in a medium age adult ( $\geq 50$ years) we must suspect an AION. This does not mean that ON or AION can occur out of this range of age, but are forms that will present atypical features. The exact pathogenic mechanisms for either ischemic or inflammation of the optic nerve remains unknown. Nowadays, there is not an effective treatment in terms of recovery to normal visual acuity, visual field or contrast sensitivity in neither of them $[10,12]$.

Compressive and infiltrative optic neuropathies can present with any clinical feature. Therefore, if there is not a clear clinical diagnosis of typical ON, image tests should be done because a diagnosis 's delate may suppose a life threatening condition [13]. The treatment is basically etiological with antibiotics, corticosteroids and/ or surgery [10].

In this text we will focus on the diagnosis approach of ON. The 
most common basis for idiopathic or multiple sclerosis- related optic neuritis (MS- ON) is an inflammatory demyelination of the optic nerve. One sign's onset of the disease is the activation of T cells which precedes changes in the cerebrospinal fluid (CF) [14]. B activated cells against myelin basic protein can be found in the CF but not in peripheral blood, which suggests a primary autoimmune disease of the CNS [15]. The clinical approach to diagnose an inflammation of the optic nerve consists in identifying some clinical features common to optic neuropathies (vision loss, RAPD and dyschromatopsia), usually presented with peribulbar pain in a short period of time. Clinical examination of these patients at first requires a well distinction of the typical and atypical features, because both the early diagnosis and treatment are overriding in the second ones.

\section{Clinical features: Typical vs. atypical optic neuritis}

Idiopathic demyelinating ON or MS- ON accounts for a considerable proportion of cases of unilateral acute or subacute vision loss in young and otherwise healthy individuals, in a range of age between 25-45 years old [16]. The Optic Neuritis Treatment Trial (ONTT) revealed that over $90 \%$ of the patients enrolled had ipsilateral peribulbar pain, usually worsened with eye movements [17]. It typically carries a good prognosis and visual acuity (VA) recovery without treatment. RAPD and color desaturation often persist despite recovery of normal vision. Basically, this pattern [young patient, unilateral, acute or subacute presentation (over a period of 1-2 weeks), pain worsened with eye movements and good prognosis] defines a typical ON [18] (Table 2). The main causes in this scenario would be idiopathic and MS- ON. Any modification of this clinical pattern should be considering atypical [19]. Other characteristics enrolled with typical ON are female patients (77\%) and Caucasian (85\%) [17]. VA reduction has a widely range. The Optic Neuritis Study Group reported a 20/40 or better: $10 \%$ were $20 / 20$, $29 \%$ were $20 / 50-20 / 190$, and $36 \%$ were $20 / 200$ or worse; $72 \%$ had a VA $\geq 20 / 20$ after 15 years of follow-up [16]. Therefore, the physician should consider this diagnosis even if VA is not clearly decreased. Red desaturation is the most sensitive indicator of dyschromatopsia, but not a very specific one. Recently, Moss et al. analyzed ONTT data and reported a relationship between Black ethnicity and poorer VA and contrast sensitivity [20]. One recent study in which 291 patients with MS and $\mathrm{ON}$ as first symptom were retrospectively reviewed, reported that men and patients with severe vision loss are more likely to have worse recovery, in contradistinction to pediatric patients, who had better visual recovery [21]. Low vitamin D levels were associated with more severe visual loss but not with VA improvement. The pathophysiology of this association remains unclear.

Edema of the optic nerve head is found in one third of cases and is typically mild, diffuse and without hemorrhages (Figure 3). Retrobulbar
$\mathrm{ON}$ is presented in two thirds of the cases [16]. Fundus exam in this case is normal. It is important to emphasize that the optic nerve head swelling is not a differential clinical feature between typical and atypical ON (do not misunderstand "typical" with "frequent"). When optic nerve head swelling is seen, it is essential to search for phlebitis (focal or diffuse), in both eyes, mostly in the equatorial zone. This sign can be easily unnoticed and it is associated with ON relapse and evolution to Multiple Sclerosis (MS). In the worst cases, optic atrophy can result from a previous intense inflammation (even in retrobulbar forms), which can be diffuse or temporal. This consequence can appear in any optic neuropathy, but it is more likely in AION.

The clinical pattern of AION can be overlapped with ON (acute monocular vision loss, RAPD and disc edema) and can be hard to differentiate in elderly patients. Peribulbar pain worsened with eye movements is a classic symptom in $\mathrm{ON}$ that can help in the differential diagnosis. However, there have been reports of mild ocular discomfort in AION in $8-12 \%$ of individuals $[3,4,18]$. If pain is a prominent complaint, AION should not be considering a likely diagnosis. Other clinical features more likely of AION are: altitudinal scotoma, often noticed upon awakening that can even progress over the first few days, amaurosis fugax, prodromal ocular or systemic symptoms in arteritic forms and history of cardiovascular risk factors [22].

Optic nerve head swelling in $\mathrm{ON}$ can be differentiated from ischemic forms through some funduscopic signs. $25 \%$ of the patients with AION have a segmental disc edema, usually involving the superior portion of the disc (due to anatomic distribution of the circle of Zinn- Haller) $[3,19,23]$. Segmental disc edema may not correspond to distribution of vision loss. Disc hyperemia with splinter or flame hemorrhages and telangiectatic capillaries are common in AION, but not in ON (Figure 4). The fellow eye often reveals a crowed optic disc with a small physiologic cup, which has been traditionally reported as "disk at risk" [24]. Technological innovations in gadolinium- contrast enhanced Magnetic Resonance Imaging (MRI), as fast espin echo (FSE), fluiattenuate inversion recovery with fat suppression techniques (FLAIR), short tau inversion recovery (STIR) or diffusion tensor imaging (DTI), have been widely investigated and appear to be a useful tool in order to discriminate ischemic from inflammatory conditions $[19,25,26]$. Thickening's magnification of the optic nerve, with regular and diffuse restriction in the diffusion sequence suggests an inflammatory disorder; optic nerve's normal size and focal restriction in the diffusion sequence suggests an ischemic disorder [27] (Figure 5). Computed tomography (CT) is necessary in atypical cases in order to see the orbit and paranasal sinuses. Nevertheless, in those cases MRI with gadolinium contrast is necessary to detect intracraneal complications and affection of intracanalicular and intracraneal portions of optic nerve. Anyway, the most valuable information of brain MRI in typical ON is its predictive

\begin{tabular}{|l|l|l|}
\hline & Typical & Atypical \\
\hline Age & $15-45$ years old & $<15 ;>45$ years old \\
\hline Side & Unilateral & Bilateral; rapidly sequencial to the fellow eye \\
\hline Onset & Acute; subacute (1-2 weeks) & Insidious; Chronic \\
\hline VA & Moderate affectation & Severe affectation \\
\hline Pain with eye movement & Present & Absent; mild discomfort \\
\hline Fundus exam & $\begin{array}{l}\text { Normal }(2 / 3) ; \text { diffuse edema without hemorrhages }(1 / 3) ; \\
\text { periphlebitis; resolved within two months }\end{array}$ & Normal; sectorial edema; hemorrhages; persistent after two months \\
\hline Evolution & $\begin{array}{l}\text { Spontaneous resolution; steroids accelerate the recovery } \\
\text { of VA }\end{array}$ & $\begin{array}{l}\text { Progression after two weeks; steroids unresponsive forms (at least two lines } \\
\text { of VA); marked steroids responsive forms }\end{array}$ \\
\hline RAPD & Present & Present \\
\hline
\end{tabular}

RAPD: Relative Afferent Pupilary Defect. If there is an optic neuropathy of the fellow eye could not be present. VA: Visual Acuity.

Table 2. Differential features between typical and atypical optic neuritis. 
Citation: Pérez Bartolomé F, García Vasco L, Abreu Ventura N, Arcos Villegas G, Santos Bueso E, et al. (2015) Diagnosis Approach of Optic Neuritis. J Neurol Neurophysiol 6: 345. doi:10.4172/2155-9562.1000345

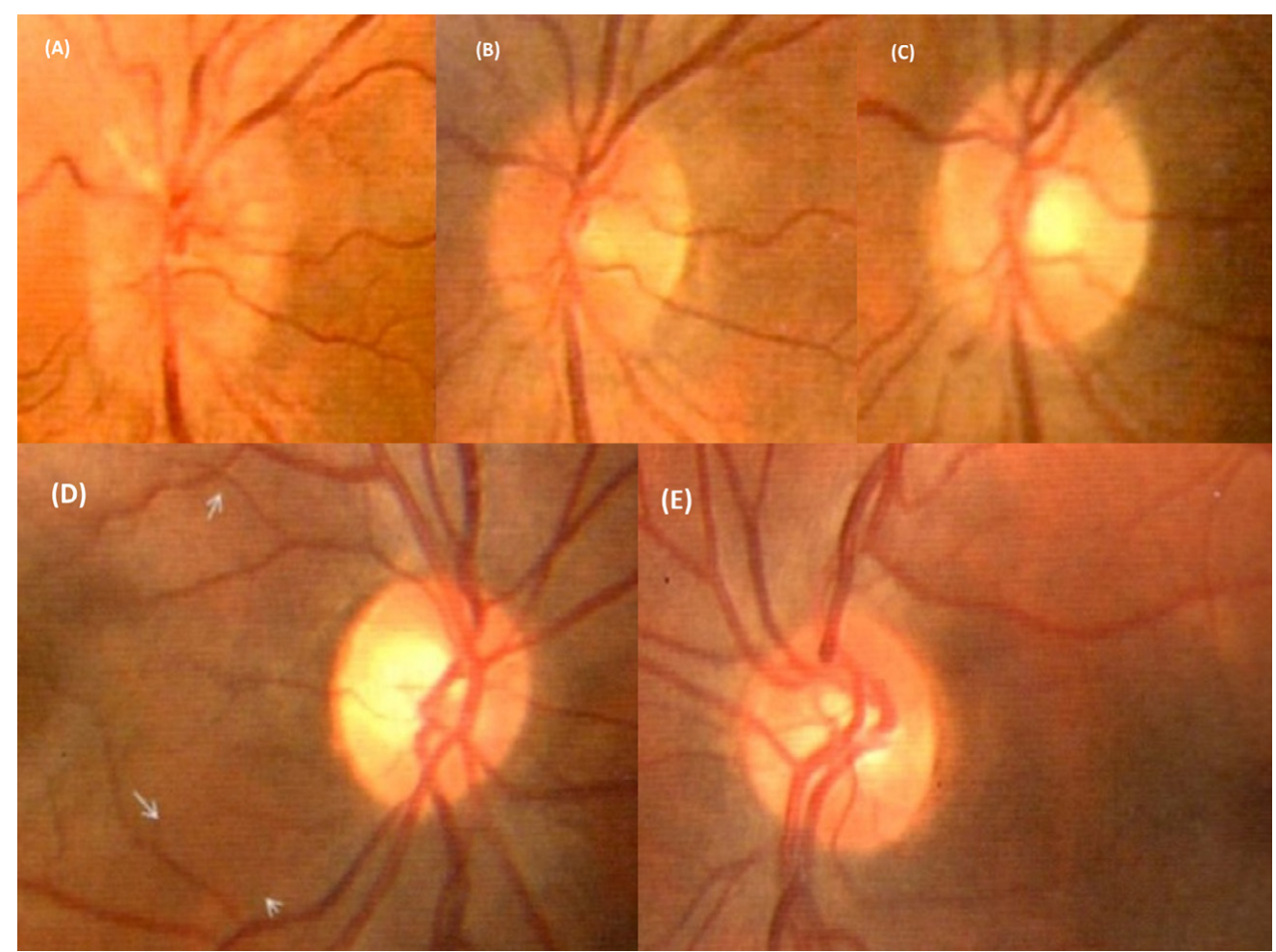

Figure 3: Superior: Evolution of an anterior MS- ON. A. Optic nerve head edema in the acute phase with reduction of VA. B. Reduction of edema. C. Complete resolution of the edema with VA reconstitution. Inferior: D. Pallor of the optic disc in the right eye with past anterior MS- ON. It is especially manifest in temporal side of neuroretinal ring when we compare it with the fellow eye (E). Courtesy of Spanish Society of Ophthalmology.

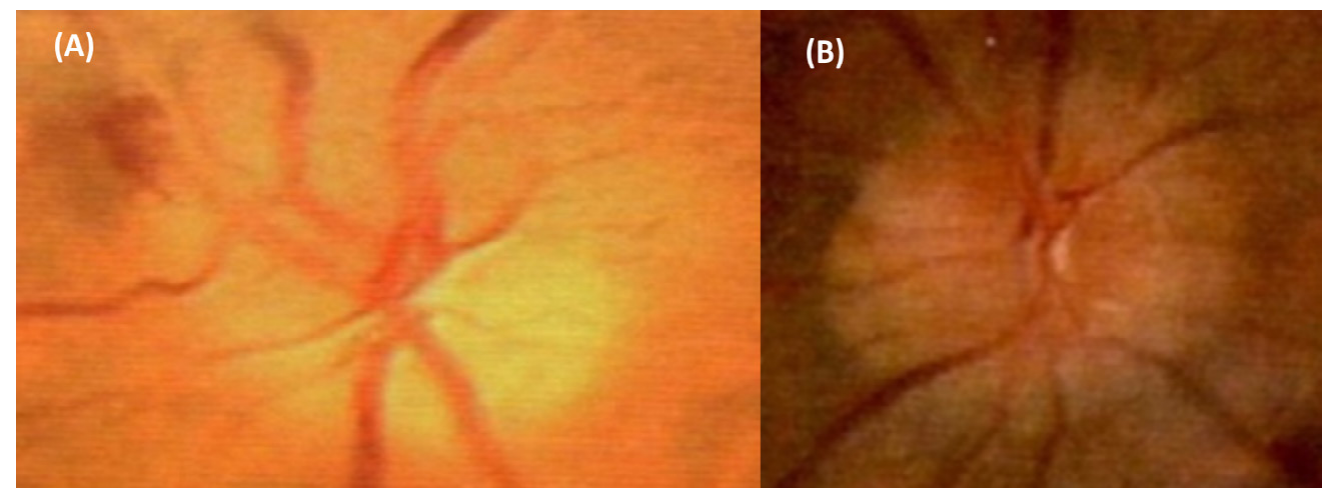

Figure 4: Differences between optic nerve head edema in AION and ON. A. AION: Superior segmental disc edema, one flame hemorrhage and attenuation of the vessels' caliber. B. ON: Diffuse edema of the optic disc without hemorrhages. Courtesy of Spanish Society of Ophthalmology.

value for risk of conversion to MS, rather than the ON diagnosis itself $[19,28]$. Therefore, clinical evaluation in these patients is essential because entails the m2ain feature to guide the decision whether or not steroid treatment is necessary. If atypical symptoms are present, the evaluation of MRI previous steroid treatment seems a prudent behavior, in order to not misdiagnose other possible etiologies and avoid treatment ineffectiveness and complications. Nevertheless, if GCAAAION is clearly suspected (acute optic neuropathy' symptoms and signs in elderly patients with increased erythrocyte sedimentation rate and reactive $\mathrm{C}$ protein) early treatment with intravenous corticosteroids is underlying in order to prevent permanent bilateral blindness, which is estimated that will develop in 25 to 50 percent of untreated patients who present with loss of vision in one eye [29]. Rebolleda et al. described, in an unmasked clinical trial, the uselessness of high-dose systemic steroid treatment when given during the acute phase of non arteritic optic neuropathy (NAION), because none beneficial effect in visual and anatomic outcomes was shown. They even described serious complications in a third of the treated patients [30]. Kinori et al. retrospectively compared two nonrandomized groups of 23 patients and concluded that high-dose intravenous treatment within 14 days of symptom onset of NAION provided no statistical benefit [31]. In the other hand, Radoi et al. noted statistically significant improvements in both visual acuity and visual fields at 6 months in 21 patients treated with corticosteroids (4 mg intravitreal triamcinolone) compared with 14 untreated [32]. Hayreh reported that corticosteroid treatment could be beneficial, in terms of VA at six months, after performing a "patient 


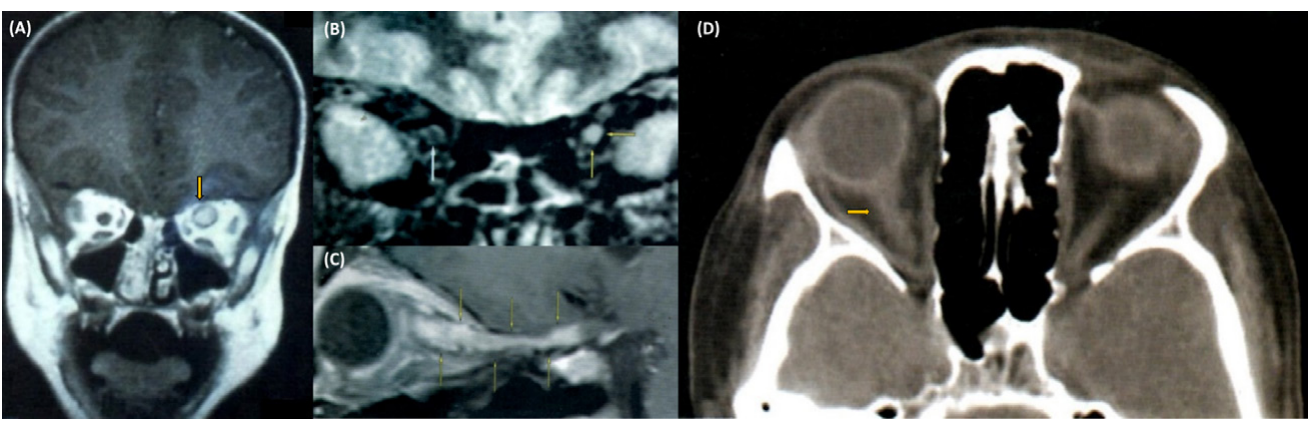

Figure 5: Imaging test showing ON. A. MRI Coronal cut. Regular thickening of the left eye proving ON (arrow). B. Another coronal cut of a different patient above orbital apex in the sequence STIR- FLAIR. Left optic nerve hyperintensity, enhancement and swelling is remarkable comparing with the right one. C. Sagittal cut of MRI in a male of 14 years old with a clinic diagnosis of ON: T1 sequence with fat suppression, showing regular hyperintensity and thickening of all the optic nerve segments between the eye and chiasm. D. Computed tomography (CT) without contrast, showing regular and diffuse thickening of the right optic nerve (arrow). Courtesy of Spanish Society of Ophthalmology.
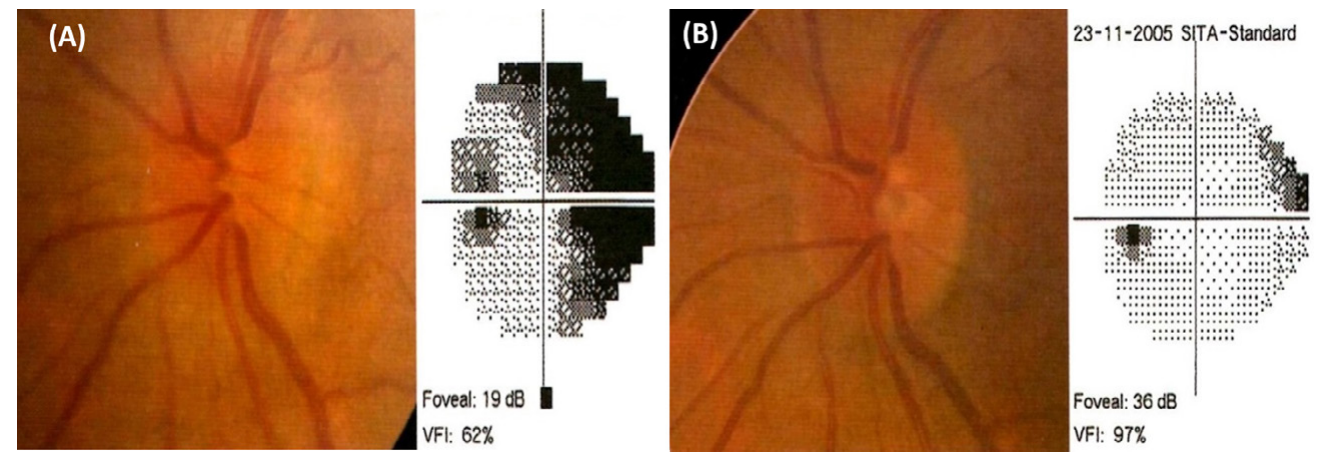

Figure 6: Humphrey SITA- Standard Perimetry. A. Papilitis of the right eye in the acute phase with arciform and cecocentral scotoma. B. Resolution of the optic nerve head edema and the VF defects within one year. Courtesy of Spanish Society of Ophthalmology.

choice" study designed with 613 consecutive patients with NAION who chose either no treatment or systemic corticosteroids $(80 \mathrm{mg} / \mathrm{d}$ for 2 weeks then tapered for approximately 8 weeks) [33]. Therefore, corticosteroid treatment for NAION remains controversial.

Known risk factors for NAION include hypertension, diabetes mellitus and hypercholesterolemia. Bilgin et al. compared 27 patients with NAION and 27 matched controls, describing a statistically higher prevalence of obstructive sleep apnea in the NAION group [34]. Posterior ischemic optic neuropathy (PION) is much rarer and usually occurs in the setting of prolonged spine or cardiac surgical procedures, giant cell arteritis or dialysis.

\section{Complementary tests in typical optic neuritis}

The visual field (VF) defect in typical ON is usually characterized by a central scotoma with diffuse sensitivity reduction $[35,36]$. In the ONTT, almost all types of visual field defects were seen, including diffuse vision loss, arcuate, altitudinal, arcuate, hemianopic and cecocentral scotomas. Accordingly, perimetry is a helpless tool for the etiology diagnosis because is unspecific. Nonetheless, is helpful in order to rule out lesions in the optic chiasm and post- chiasm pathway by identifying bilateral defects which respect the vertical meridian. Traquair scotoma (union scotoma) is a rare pattern that was classically defined as a small superior-temporal scotoma in the fellow eye due to a lesion in the nasal fibers close to the optic chiasm. A defect that extends to the periphery should suggest a compressive lesion while an altitudinal defect is more common in AION $[35,36]$. VF defects usually have good prognosis and get improved while resolution of edema and VA takes place, independently of the initial severity (Figure 6). In the ONTT, almost $73 \%$ of the patients had normalized VA at 10 years [37,38]. Automatic static perimetry has practically replaced kinetic perimetry (Goldmann). Humphrey full-threshold SITA standard VF has been the most widely perimetry used to study, not only optic neuropathies, but also the whole afferent vision pathway. Both horizontal and vertical VF meridians are best delineated with Humphrey rather than Octopus TOP. Nonetheless, variability of the VF is considerable during the follow up of these patients. Therefore, it may be replaced in the near future by other test with more sensitivity and reproducibility like OCT [39].

As we said before, MRI of the brain and orbits with gadolinium contrast provides confirmation of the diagnosis of acute demyelinating optic neuritis but it is not indispensable for the diagnosis. Global and longitudinal enhancement of the nerve is the typical pattern, and it's extension has been shown to correlate with visual impairment and with visual prognosis $[40,41]$. Enhancement can persist for a mean of 30 days since onset, even after recovery of vision [42]. Davies MB et al. observed that signal abnormality in the nerve is also present in at least $60 \%$ of patients with MS who do not have a clinical history of optic neuritis [43]. Brain MRI is essential in these patients in order to determine the risk of developing MS in the near future. In ONTT, 40\% of the patients presented white matter demyelinating abnormalities characteristic of MS, but other case series have noticed at least $40-60 \%$ of MRI brain lesions at first episode of ON [44]. Global risk at 15 years is estimated as $50 \%$, and gets increased with the number of lesions observed. Normal MRI reduces the risk of conversion to MS into $25 \%$. Marques et al have recently reported a retrospectively evaluation of 
patients with normal brain MRI at the time of the first episode of $\mathrm{ON}$ to determine conversion to MS. 10 of the 42 patients developed MS during an 8-year follow-up, which suppose a less rate than reported in ONTT. Nonetheless, this study has a much lower sample size and the median follow up was too much shorter. Other reported data similar to ONTT was a more likely conversion when previous symptoms suggestive of MS, presence of cerebrospinal fluid oligoclonal bands and incomplete visual recovery were present. Optic disc swelling correlated with a lower MS conversion rate [45]. It is important to mention that a normal MRI does not protect from MS at $100 \%$, the same way that pathological ones do not sentence the development of MS [45].

OCT measures the thickness in the peripapillary retinal nerve fiber layer (RNFL) without myelin and, therefore, quantifies the axonal injury, which has been shown to correlate with persistent visual dysfunction [46] (Table 3). Nevertheless, in acute phases the utility of OCT as a prognostic tool is limited in that abnormal values do not show up until early swelling disappears. In this phase, RNFL thickening appears (Figure 7). A month and half since the acute phase, RNFL thinning can be seen in most of patients (51-74\%) with optic neuritis, even if VA rises up to normality [47-49]. Recently, Kupersmith et al. prospectively studied the RNFL with OCT in 25 patients 1 month and 6 months after they had acute ON. They found that one month RNFL thickness correlated with 6-month thickness and thus could predict the structural outcome of the ON attack [50]. RNFL thinning is also common in patients with MS who do not have a clinical history of optic neuritis, but in a smaller range than ones who do [51]. Recently has been reported the significant correlation between RNFL thinning and atrophy of the posterior visual pathways and visual ina cross- sectional study with 100 patients with MS and posterior visual pathway damage [52]. Karl C Golnik suggests in a recent review that this could mean the possibility of transsynaptic degeneration [10]. Neither the presence or absence of disc edema, or it's severity, have a prognosis value for visual outcome, RNFL thinning or VF defects in acute phase. The biological parameters that do really correlates with RNFL thinning are vision loss in the acute phase and the number of recurrences of ON. High-dose systemic steroid treatment does not affect final RNFL values [53]. RNFL thinning implies structural damage and a lower probability of VA recovery. A greater severity of optic nerve injury seen on OCT suggests neuromyelitis optica (NMO) rather than MS-ON [54]. OCT is a higher sensible test than perimetry for detection of subclinical damage once the acute phase has been resolved [55]. New macular layers segmentation softwares for Cirrus and Spectralis OCT have been recently studied in neuro-ophthalmologic patients. GónzalezLópez JJ et al. stated that macular ganglion cell-inner plexiform layer (GCIPL) thickness measured with Spectralis and Cirrus OCT had a better sensibility than peripapillary retinal nerve fiber layer (pRNFL) for detecting retinal thickness changes in patients with relapsingremitting multiple sclerosis [56]. Nonetheless, in one study, OCT was less sensitive than visual evoked response (VER) in detecting subclinical optic neuritis, seen as a delay in the P100 wave, which is the electrophysiological manifestation of slowed conduction in the optic nerve as a result of axonal demyelination [57]. After visual recovery, the pattern-shift visual evoked response can still be delayed in most patients [58].Thus, VER is useful to diagnose subclinical, latent, past or doubtful episodes of ON, but has not any value in the acute phase.

In a young adult with one clinical diagnosis of typical ON and normal MRI, atypical causes are exceptional. Therefore, if there are no other clinical findings, complementary test should not be performed.

\section{Treatment of Typical Optic Neuritis}

\section{Visual acuity recovery}

Corticosteroids have been widely used for treatment in the acute phase of idiopathic or MS-ON. Patients in the ONTT were randomly assigned to either oral prednisone; intravenous methylprednisolone followed by oral prednisone or oral placebo. Patients were treated within eight days of symptom onset. The primary visual outcomes were VA and contrast sensitivity [59]. None of the treatment arms of the

1. Confirm and quantifies the edema of the optic nerve head.

2. Quantifies RNFL thickness, which correlates with VF parameters, VER and VA in the acute phase.Detect subclinical damage of RNFL in patients diagnosed of MS (subclinical death of ganglion cell axons).

3. Detect subclinical changes of GCIPL thickness

4. OCT is more sensible tan perimetry to detect MS- ON

RNFL: Retinal Nerve Fiber Layer; VF: Visual Field; VER: Visual Evoked Response; VA: Visual Acuity; GCIPL: Ganglion Cell-Inner Plexiform Layer

Table 3: Applications of optic coherence tomography (OCT) in multiple sclerosis- like optic neuritis (MS-ON).

(A)
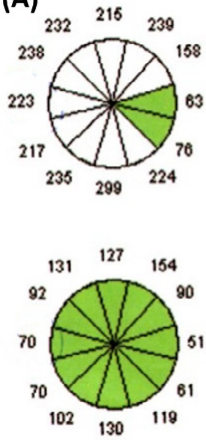
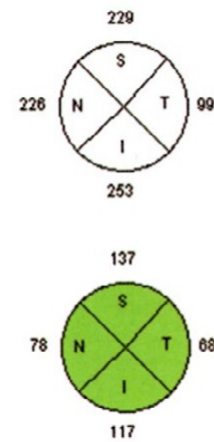
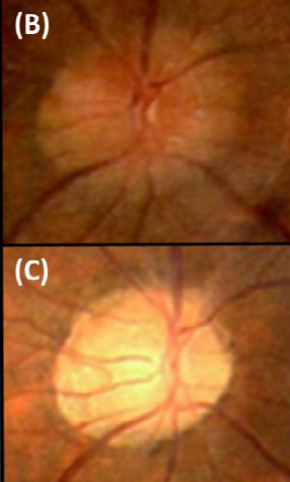
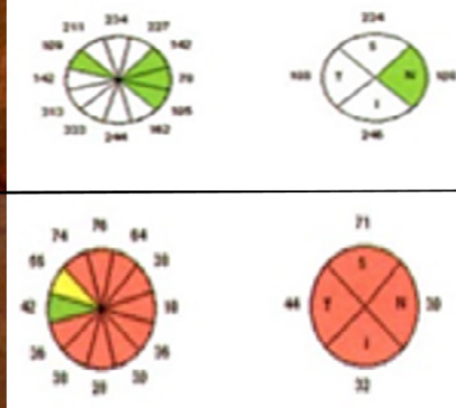

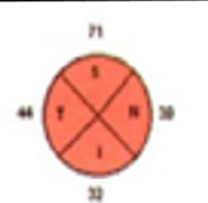

Figure 7: OCT. A. Cirrus OCT corresponding of the patients of Figure. 6 . There is a significant thickening of RNFL (superior) in the acute phase (optic nerve head edema) with normal RNFL thickness within one year (inferior). B. Anterior ON in a young female patient with RNFL thickening in three of four quadrants. C. Within three months there is a diffuse pallor of the optic nerve head with severe thinning of the four quadrants. Courtesy of Spanish Society of Ophthalmology. 
study overcame the natural history of the disease. Most of the patients reached spontaneously good visual outcomes. The main conclusion of this trial was that intravenous methylprednisolone accelerated the recovery of visual function; however one-year visual outcomes were similar among treatment groups. A meta-analysis of various trials, including this one, that compared treatment with intravenous methylprednisolone to placebo found no benefit of treatment on visual outcomes at six months and at one year [60]. The oral prednisone arm of the study was found to have a higher two-year risk of recurrent optic neuritis in both eyes, when compared with intravenous steroid therapy or with placebo. Nevertheless, a small randomized trial found out that oral methylprednisolone had a beneficial effect on visual function at one and three weeks compared with placebo, without differences between treatment groups with regard to visual outcome at eight weeks or to the risk of developing additional demyelinating events at one year [61]. Therefore, the observed risks associated with oral prednisone were only seen in ONTT, were unexpected and had no pathophysiological basis. The side effects of steroid treatment in this scenario are exceptional. The most common side effects in the ONTT were facial flushing, sleep perturbations, mood changes and weight gain [59]. Alternative treatments proposed for $\mathrm{ON}$ has been intravenous immunoglobulin (IVIG) and plasma exchange, but neither of them have proved efficacy (statistical difference in visual outcomes at six months) $[62,63]$. If VA rise up very fast after Corticosteroids treatment, other autoimmune causes should be suspected rather than MS- ON, such as sarcoidosis, lupus or vasculitis (see "atypical optic neuritis" below).

\section{Prevention of Development of Multiple Sclerosis}

An important clinical decision in patients with optic neuritis is whether or not to begin immunomodulatory therapy in order to prevent, or at least delay, subsequent MS. The two bigger clinical trials that have studied this outcome have been CHAPMS (Controlled HighRisk Subjects Avonex Multiple Sclerosis Prevention Study) and ETOMS (Early Treatment of Multiple Sclerosis) [64,65]. Both of them studied interferon beta-1a as an immunomodulatory drug versus placebo (the first one by intramuscular administration and the second one by subcutaneous). The patients recruited had clinically isolated syndromes (192 ON in CHAPMS and 98 ON in ETOMS) and were at high risk for developing MS (defined as two or more demyelinating lesions on their brain MRI in CHAMPS and at least four white matter lesions or three lesions with at least one demonstrating gadolinium enhancement in ETOMS). Both trials concluded that the risk of developing significant MS was delayed after two years of follow up. Other clinical trials, which have evaluated interferon-1b (BENEFIT) and glatiramer acetate (PreCISe), also proved that early treatment in patients with clinically isolated syndromes, including optic neuritis, reduces the rate of MS development $[66,67]$. Posterior trials compared early with belated interferon therapy and concluded statistical differences between the disability progression, but the benefit of early treatment was clinically poor significant. Even more, this studies evaluated patients with a very high number of MRI lesions ( $>9$ ) and multifocal syndromes. Thus, were not applicable to patients with isolate $\mathrm{ON}$ [68]. Common side effects of beta interferon treatment in these trials included depression, flu-like symptoms and injection site reactions; elevated liver enzymes were seen in a significant number of patients [66]. Newer immunotherapies for MS are currently being investigated (teriflunomide, alemtuzumab, fingolimod, dimethyl fumarate, natalizumab) and some of them are already being used. They offer advantages of efficacy or tolerability over the injectable therapies, but they also have greater risks [69].

Therefore, according to the actual knowledge, nowadays both the absence of treatment and intravenous or oral steroid treatment are justifiable attitudes. If the patients tolerates, immunomodulatory therapy should be offered in cases of high risk of conversion to MS (subclinical demyelinating lesions in MRI).

\section{Atypical Optic Neuritis}

The common characteristics of atypical $\mathrm{ON}$ are summarized in table 2. In children, para-infectious causes of optic nerve impairment should be considered as alternatives to MS- ON. It is very common the history of recent upper respiratory tract symptoms. Post-viral ON has been associated with measles, mumps, chickenpox, influenza, and Epstein-Barr, typically following the clinical infection by one to three weeks 58 [70]. Usually the prognosis is excellent with full vision recovery. Rappoport et al. reported a study with their experience and compared ten children and eight adults with para-infectious optic neuritis followed up for 8-years. They found that all patients had optic disc swelling and good visual outcomes. Nevertheless, children were more likely to have bilateral optic neuritis and disseminated encephalomyelitis [71]. They defined para-infectious optic neuritis as an ON occurring after an infectious disease (within one month), probably on an autoimmune basis.

As we have mentioned, in an older patient ( $>50$ years old) ischemic optic neuropathy is the most likely diagnosis. Alternative diagnoses from idiopathic or MS- ON should be considered in patients with a painless or bilateral presentation; early corticosteroids responsive and corticosteroids unresponsive situations, the presence of neurologic or systemic symptoms and in immunocompromised patients.

\section{Leber's hereditary optic neuropathy}

Leber's hereditary optic neuropathy (LHON) should be consider in patients with subacute and painless vision loss in one eye, with sequential involvement of both eyes over a period of weeks to months; especially in those whose vision does not improve over time [72]. This disorder is inherited through a mitochondrial respiratory chain DNA mutation, so effects young males predominantly. Three mutations account for more than 90 percent of worldwide cases [73]. The classic fundus appearance in the acute phase includes pseudoedema of the optic nerve head with peripapillary telangiectasia and tortuous vessels (Figure 8). Nonetheless, one third of the patients can have a normal fundus exam [74]. Typically, fluorescein angiogram (FA) does not show peripapillary leakage. There are currently no proven treatments for LHON, but promising novel treatment modalities are being evaluated in several trials, such as Idebenone, a synthetic analog of coenzyme Q10 [75]. Nowadays, prognosis for recovery varies depending on the mutation [76].

Other acute, unilateral or painless presentations that could be misdiagnosed with $\mathrm{ON}$ are retinal vein occlusion and central serous chorioretinopathy. Fundus exam, FA and OCT are enough to confirm the diagnosis of these entities.

\section{Neuromyelitis Optica}

NMO (Devic disease) is an autoimmune demyelinating disorder which consist in ON (typically bilateral or unilateral rapidly sequential to the fellow eye) and transverse myelitis (TM) [77] (Figure 9). Attacks leads to severe vision loss and most often occur over days, generally with poor vision recovery over weeks to months. It has typically a relapsing course, and both anterior or retrobulbar optic nerve portion can be affected [78]. In this case, the prevalence in women is up to 10 times higher than in men [79]. The exactly pathogenesis remains unknown, but it is 
Citation: Pérez Bartolomé F, García Vasco L, Abreu Ventura N, Arcos Villegas G, Santos Bueso E, et al. (2015) Diagnosis Approach of Optic Neuritis. J Neurol Neurophysiol 6: 345. doi:10.4172/2155-9562.1000345

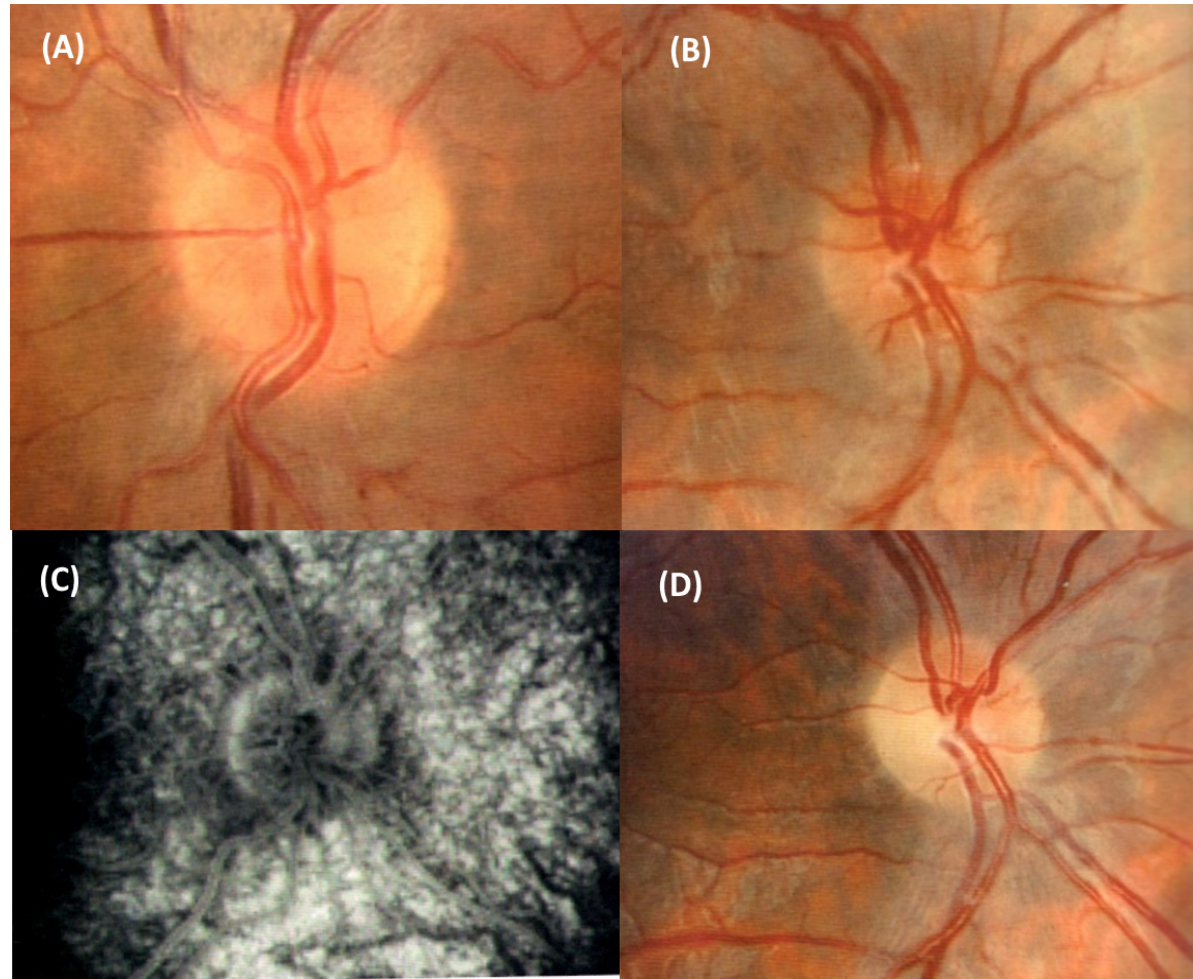

Figure 8: Leber's hereditary optic neuropathy. Superior. Both the left and the right images correspond to a young male with acute right anterior optic neuropathy (B) and rapidly sequential affection of the left eye (A). Notice the peripapillar telangiectasia. Inferior. C. FA showing absence of peripapillary leakage (pseudoedema). D. Evolution to optic atrophy. Courtesy of Spanish Society of Ophthalmology.

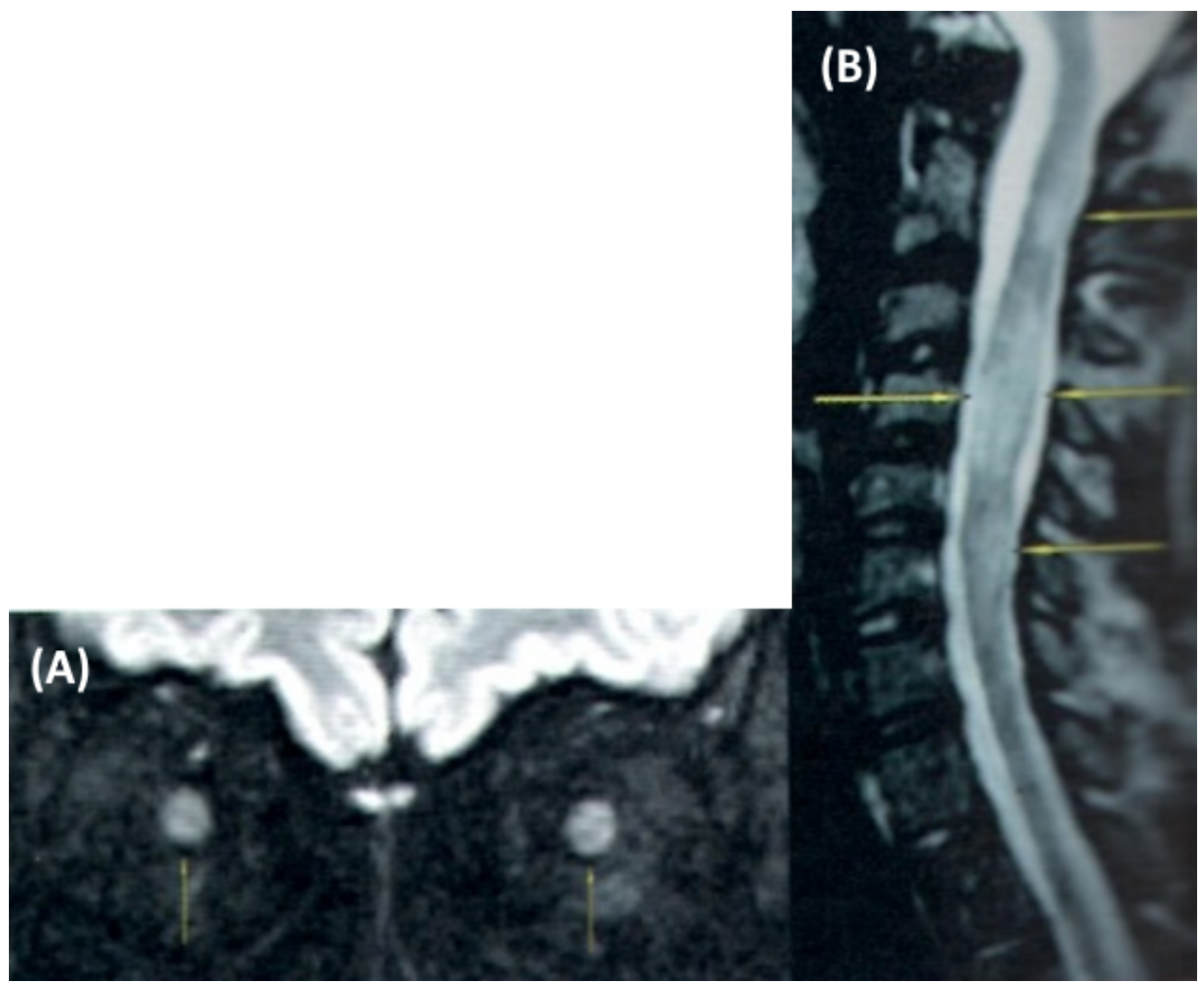

Figure 9: MRI of NMO. A. MRI coronal cut (sequence STIR- FLAIR) of the orbits showing bilateral hyperintensity and enhancement of both optic nerves (bilateral ON) (arrows). B. Four months later the patient developed TM. Cervical MRI sagittal cut showing hyperintense lesions in sequence T2 in C2- C7 segments (arrows). Courtesy of Spanish Society of Ophthalmology. 
Citation: Pérez Bartolomé F, García Vasco L, Abreu Ventura N, Arcos Villegas G, Santos Bueso E, et al. (2015) Diagnosis Approach of Optic Neuritis. J Neurol Neurophysiol 6: 345. doi:10.4172/2155-9562.1000345

known that auto- antibodies IgG against Aquaporin-4 (AQP4), a water channel protein highly concentrated in spinal cord gray matter, causes an autoimmune inflammatory cascade that leads to demyelination and axonal injury through diverse pathways [80]. Lim et al reported recently that female sex and bilateral involvement at presentation are more likely in NMO patients than in MS-ON [81]. International consensus diagnostic criteria for neuromyelitis optica spectrum disorders (NMOSD) have been reviewed [82]. Briefly, diagnosis confirmation of NMO should be done with at least one "clinical core characteristic" (ON/TM, simultaneously or not) and at least two of the three following criteria: spinal cord lesions in at least three adjacent segments, brain lesions not compatible with MS or a positive result for NMO antibodies (AQP4 IgG). Spinal lesions tend to be extended and hyperintense in T2 sequence. Petzold and Plant have published recently a review of autoimmune optic neuropathies in which recommend testing for NMO antibodies in all patients with severe, atypical, or recurrent optic neuritis [83]. Treatment includes intravenous glucocorticoids, followed by plasmapheresis and a long-term immunosuppression in order to prevent subsequent attacks. Recommended first-line treatments include azathioprine and rituximab. The relapse rate has been shown to be decreased with the use of rituximab in one study with 5-year follow-up [84]. Mycophenolate, methotrexate and mitoxanthrone are considered second-line treatments.

\section{Chronic relapsing inflammatory optic neuritis}

Chronic relapsing inflammatory ON (CRION) is a modern term that describes relapsing episodes of $\mathrm{ON}$ which are clearly responsive to corticosteroids, in patients with normal imaging test, CSF and serological testing for other autoimmune or infectious diseases [85]. This entity was initially evolved in the NMOSD, but it has been proved that only $5 \%$ of these patients are seropositive for AQP4 IgG [86]. Therefore, MS and NMO are the mainly differential diagnosis. Petzold and Plant proposed revised criteria for diagnosis including at least 2 episodes of optic neuritis, NMO-IgG negative, contrast enhancement of the inflamed optic nerve in MRI and response to immunosuppressive treatment with relapse on withdrawal of treatment [87]. Treatment with intravenous steroids are necessary in the acute phases and immunosuppressing drugs, such as azathioprine, methotrexate, cyclophosphamide or mycophenolate, are obligated in order to prevent further episodes of ON [88-90].

\section{Paraneoplastic Optic Neuritis}

Paraneoplastic ON has been described as a cause of bilateral ON, usually presented with subacute visual loss and other neurologic symptoms, including neuromuscular junction disorders (LambertEaton myasthenic syndrome), autonomic neuropathy, dementia, ataxia and chorea [91]. It has also been described the association with paraneoplastic encephalomyelitis or retinitis [92]. This disorder is most commonly associated with lung cancer but other forms of cancer have been implicated [93]. Antibodies against collapsing response-mediator protein-5 (CRMP-5) seem to be a good biomarker for the diagnosis [94].

\section{Sarcoidosis, Vasculitis and Systemic Lupus Erythematous}

Relapsing forms of ON, especially closely after cessation of corticosteroids, is highly suggestive of an inflammatory optic neuropathy different from MS- ON or NMO. In this scenario, three main causes should be considered: sarcoidosis, vasculitis and systemic lupus erythematous (SLE). ON is the main neuro-ophthalmologic manifestation of neurosarcoidosis, usually with optic nerve head swelling (Figure 10). It can be caused through four main mechanisms: papilitis, posterior uveitis, granuloma of the optic nerve and $\mathrm{ICH}$

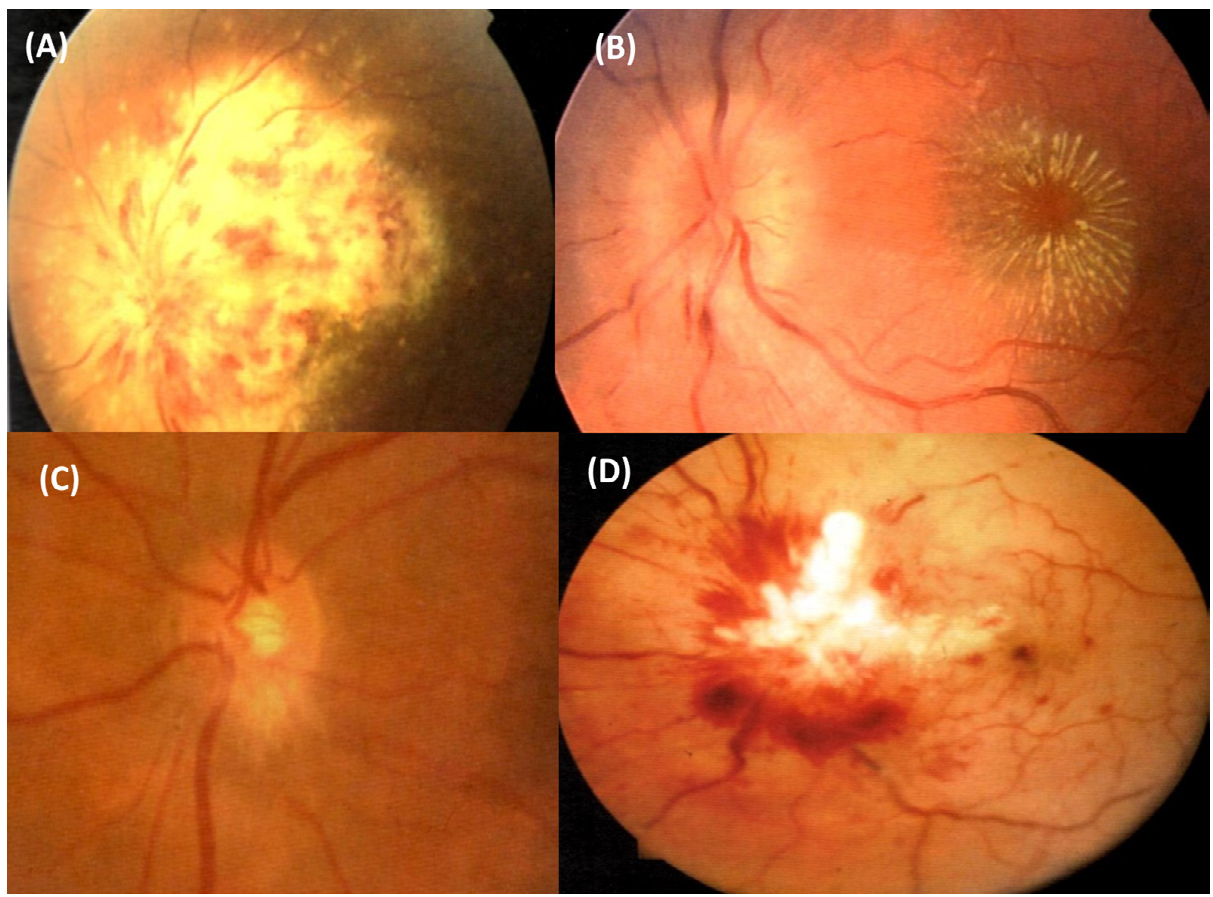

Figure 10: Other atypical causes of optic neuropathy. A. Citomegalovirus retinitis in a patient with AIDS. B. Neuroretinitis: Notice the optic nerve swelling and the macular edema with hard exudates around the fovea. C. Sarcoid granuloma of the optic nerve head. D. Infiltrative optic neuropathy due to lekemia. Courtesy of Spanish Society of Ophthalmology. 
[95]. Vasculitis and SLE should be suspected in young patients with corticosteroid- responsive forms and serologic evidence of autoimmune disease. "Autoimmune $\mathrm{ON}^{\circ}$ " is a diagnosis of exclusion in which systemic manifestations are absent and MRI is normal, but nonspecific serologic autoimmune disorder is present (positive result for antinuclear antibodies, rheumatoid factor etc) or there is a cutaneous biopsy compatible with collagenous disease or vasculitis [96].

\section{Compressive or infiltrative optic neuropathies}

Persistent visual loss beyond four weeks of onset of ON, after corticosteroid treatment, generally signifies an alternative diagnosis. A compressive or infiltrative cause of optic neuropathy should be suspected in these cases. Thyroid eye disease frequently results in optic neuropathy from compression by enlarged extraocular muscles in the orbital apex. Orbital decompression is still generally considered to be the treatment of choice to alleviate this compressive optic neuropathy. Curro et al. retrospectively evaluated the efficacy of pulsed methylprednisolone for thyroid optic neuropathy in 44 of 24 patients and concluded that forty percent of patients had resolution of optic neuropathy without requiring orbital surgery [97]. Pituitary adenoma, carcinomatous meningitis, glioma, infiltrative leukemia o even aneurysms are possible etiologies. In this scenario, any clinical manifestation can be presented (acute, subacute, chronic vision loss, headache, orbital pain, etc.). Therefore, neuro-imaging tests are obligated for the diagnosis.

\section{Infectious Optic Neuritis}

Infectious causes of optic neuropathy should be suspected in patients with history of potential exposures and/or immunosuppression. A 7\% of patients seropositive for HIV with cerebral toxoplasmosis, cryptococcus or tuberculous meningitis present papilitis. Neuretinitis is a descriptive diagnosis that present with vision loss, optic nerve head edema along subretinal fluid and macular edema, usually with hard exudates in the posterior pole. Bartonella Henseale (cat scratch disease) and Borrelia Burgdorferi (Lyme disease) are usual suspects [98] (Figure $10)$.

\section{Conclusion}

The diagnosis of $\mathrm{ON}$ is mainly clinical. Typical cases of $\mathrm{ON}$ are defined as painful, monocular visual loss evolving over several hours to a few days, in young adults with generally good prognosis. One-third of these patients have visible optic nerve inflammation on funduscopic examination; in the remainder, the inflammation is retrobulbar. This clinical pattern is more likely due to a demyelinating process and closely associated with MS, although sometimes occurs in isolation. Typical ON tends to resolves spontaneously. Both the absence of treatment and intravenous or oral steroid treatment are justifiable attitudes. Experts recommend treatment if visual loss is functionally disabling or if the patient has pre-existing visual impairment of the other eye. Immunomodulatory therapy should be offered in cases of high risk of conversion to MS (subclinical demyelinating lesions in MRI). In cases of first clinical diagnosis of typical ON and normal MRI, atypical causes are exceptional. Brain MRI is essential in patients with typical ON in order to determine the risk of developing MS. Other complementary tests that should be performed in this patients are VF perimetry and OCT. VER is useful to diagnose past or doubtful episodes of ON, but has not any value in the acute phase. If atypical features develop or recovery does not begin, the atypical pathway for investigations and treatment should be performed. Higher dose of intravenous corticosteroids and, sometimes, chronic immunosuppression, are frequently required. If untreated, atypical ON can lead to irreversible visual loss.

\section{Acknowledgements}

The first author thanks Dr. Muñoz Negrete, Dra. Rebolleda Fernández and the Spanish Society of Ophthalmology for the awarding of the images shown in this article. Most of them appears in the book "Protocolos en Neuro- oftalmología. Mesa Redonda. Sociedad Española de Oftalmología. Madrid, 2010. Rebolleda G Muñoz- Negrete FJ." None of the authors has conflict of interest and no financial support was received.

\section{References}

1. Glaser JS (1990) Topical Diagnosis. Prechiasmal visual pathways. In: NeuroOphthalmology. Glaser JS (edn). JB Lippincot, Philadelphia 83.

2. Sadun AA (2004) The afferent visual System: Anatomy and physiology. In Ophthalmology, 2nd, Yanoff M, Duker JS (edn), Mosby, St. Luis 186.

3. (1996) Characteristics of patients with nonarteritic anterior ischemic optic neuropathy eligible for the Ischemic Optic Neuropathy Decompression Trial. Arch Ophthalmol 114: 1366-1374

4. Swartz NG, Beck RW, Savino PJ, Sergott RC, Bosley TM, et al. (1995) Pain in anterior ischemic optic neuropathy. J Neuroophthalmol 15: 9-10.

5. (1991) The clinical profile of optic neuritis. Experience of the Optic Neuritis Treatment Trial. Optic Neuritis Study Group. Arch Ophthalmol 109: 1673-1678.

6. Obuchowska I, Mariak Z (2006) [Ischemic optic neuropathy. Pathogenesis, clinical features, diagnostics and treatment]. Klin Oczna 108: 238-242.

7. Choi J, Kook MS2 (2015) Systemic and Ocular Hemodynamic Risk Factors in Glaucoma. Biomed Res Int 2015: 141905.

8. Balcer LJ (2006) Clinical practice. Optic neuritis. N Engl J Med 354: 1273-1280

9. Rebolleda G, Muñoz- Negrete FJ (2010) Protocolos en Neuro- oftalmología Mesa Redonda. 86 Sociedad Española de Oftalmología. Madrid. P. 17.

10. Golnik KC (2015) Neuro-Ophthalmology Annual Review. Asia Pac J Ophthalmol (Phila) 4: 307-315.

11. Peragallo JH, Newman NJ (2015) Is there treatment for Leber hereditary optic neuropathy? Curr Opin Ophthalmol 26: 450-457.

12. Gal RL, Vedula SS, Beck R (2015) Corticosteroids for treating optic neuritis Cochrane Database Syst Rev

13. Rebolleda G, Muñoz- Negrete FJ (2010) Protocolos en Neuro- oftalmología Mesa Redonda. Sociedad Española de Oftalmología. Madrid. P. 19.

14. Roed H, Frederiksen J, Langkilde A, Sørensen TL, Lauritzen M, et al (2005) Systemic T-cell activation in acute clinically isolated optic neuritis. J Neuroimmunol 162: 165-172.

15. Söderström M, Link H, Xu Z, Fredriksson S (1993) Optic neuritis and multiple sclerosis: anti-MBP and anti-MBP peptide antibody-secreting cells are accumulated in CSF. Neurology 43: 1215-1222.

16. (1991) The clinical profile of optic neuritis. Experience of the Optic Neuritis Treatment Trial. Optic Neuritis Study Group. Arch Ophthalmol 109: 1673-1678.

17. McDonald WI (1983) Doyne lecture. The significance of optic neuritis. Trans Ophthalmol Soc U K $103: 230-246$.

18. Rizzo JF, Lessell S (1991) Optic neuritis and ischemic optic neuropathy Overlapping clinical profiles. Arch Ophthalmol 109: 1668-1672.

19. Tur C, Thompson AJ (2015) Early accurate diagnosis crucial in multiple sclerosis. Practitioner 259: 21-27, 2-3.

20. Moss HE, Gao W, Balcer LJ, Joslin CE (2014) Association of race/ethnicity with visual outcomes following acute optic neuritis: an analysis of the Optic Neuritis Treatment Trial. JAMA Ophthalmol 132: 421-427.

21. Malik MT, Healy BC, Benson LA, Kivisakk P, Musallam A, et al. (2014) Factors associated with recovery from acute optic neuritis in patients with multiple sclerosis. Neurology 82: 2173-2179.

22. Hayreh SS, Podhajsky PA, Zimmerman B (1997) Nonarteritic anterior ischemic optic neuropathy: time of onset of visual loss. Am J Ophthalmol 124: 641-647.

23. Hayreh SS, Zimmerman MB (2007) Optic disc edema in non-arteritic anterior ischemic optic neuropathy. Graefes Arch Clin Exp Ophthalmol 245: 1107-1121.

24. Hayreh SS (1981) Anterior ischemic optic neuropathy. Arch Neurol 38: 675-678.

25. Barker GJ (2000) Technical issues for the study of the optic nerve with MRI. J Neurol Sci 172 Suppl 1: S13-16. 
Citation: Pérez Bartolomé F, García Vasco L, Abreu Ventura N, Arcos Villegas G, Santos Bueso E, et al. (2015) Diagnosis Approach of Optic Neuritis. J Neurol Neurophysiol 6: 345. doi:10.4172/2155-9562.1000345

26. Jackson A, Sheppard S, Laitt RD, Kassner A, Moriarty D (1998) Optic neuritis: MR imaging with combined fat- and water-suppression techniques. Radiology 206: 57-63.

27. Gomez-Porro P, Novo-Ponte S, Contador-Munana JM, Rodriguez-Esparragoza L, Brea-Alvarez B, et al. (2015) The usefulness of 3T magnetic resonance in the differential diagnosis of ischemic optic neuropathy and inflammatory optic neuritis. Rev Neurol 61: 284-285.

28. Rebolleda G, Muñoz- Negrete FJ (2010) Protocolos en Neuro- oftalmología. Mesa Redonda. Sociedad Española de Oftalmología. Madrid. P. 30.

29. Aiello PD, Trautmann JC, McPhee TJ, Kunselman AR, Hunder GG (1993) Visual prognosis in giant cell arteritis. Ophthalmology 100: 550-555.

30. Rebolleda G, Pérez-López M, Casas-LLera P, Contreras I, Muñoz-Negrete FJ (2013) Visual and anatomical outcomes of non-arteritic anterior ischemic optic neuropathy with high-dose systemic corticosteroids. Graefes Arch Clin Exp Ophthalmol 251: 255-260.

31. Kinori M, Ben-Bassat I, Wasserzug Y, Chetrit A, Huna-Baron R (2014) Visual outcome of mega-dose intravenous corticosteroid treatment in non-arteritic anterior ischemic optic neuropathy - retrospective analysis. BMC Ophthalmol 14: 62 .

32. Radoi C, Garcia T, Brugniart C, Ducasse A, Arndt C (2014) Intravitreal triamcinolone injections in non-arteritic anterior ischemic optic neuropathy. Graefes Arch Clin Exp Ophthalmol 252: 339-345.

33. Hayreh SS, Zimmerman MB (2008) Non-arteritic anterior ischemic optic neuropathy: role of systemic corticosteroid therapy. Graefes Arch Clin Exp Ophthalmol 246: 1029-1046.

34. Bilgin G, Koban Y, Arnold AC (2013) Nonarteritic anterior ischemic optic neuropathy and obstructive sleep apnea. J Neuroophthalmol 33: 232-234.

35. Balcer LJ (2006) Clinical practice. Optic neuritis. N Engl J Med 354: 1273-1280.

36. Gerling J, Meyer JH, Kommerell G (1998) Visual field defects in optic neuritis and anterior ischemic optic neuropathy: distinctive features. Graefes Arch Clin Exp Ophthalmol 236: 188-192.

37. Keltner JL, Johnson CA, Spurr JO, Beck RW (1994) Visual field profile of optic neuritis. One-year follow-up in the Optic Neuritis Treatment Trial. Arch Ophthalmol 112: 946-953.

38. Beck RW, Gal RL, Bhatti MT, Brodsky MC, Buckley EG, et al. (2004) Visua function more than 10 years after optic neuritis: experience of the optic neuritis treatment trial. Am J Ophthalmol 137: 77-83.

39. Rebolleda G, Muñoz- Negrete FJ (2010) Protocolos en Neuro- oftalmología. Mesa Redonda. Sociedad Española de Neurología. Madrid. P. 28.

40. Kupersmith MJ, Alban T, Zeiffer B, Lefton D (2002) Contrast-enhanced MRI in acute optic neuritis: relationship to visual performance. Brain 125: 812-822.

41. Rizzo JF, Andreoli CM, Rabinov JD (2002) Use of magnetic resonance imaging to differentiate optic neuritis and nonarteritic anterior ischemic optic neuropathy. Ophthalmology 109: 1679-1684.

42. Hickman SJ, Toosy AT, Miszkiel KA, Jones SJ, Altmann DR, et al. (2004) Visual recovery following acute optic neuritis--a clinical, electrophysiological and magnetic resonance imaging study. J Neurol 251: 996-1005.

43. Davies MB, Williams R, Haq N, Pelosi L, Hawkins CP (1998) MRI of optic nerve and postchiasmal visual pathways and visual evoked potentials in secondary progressive multiple sclerosis. Neuroradiology 40: 765-770.

44. (1991) The clinical profile of optic neuritis. Experience of the Optic Neuritis Treatment Trial. Optic Neuritis Study Group. Arch Ophthalmol 109: 1673-1678.

45. Marques IB, Matias F, Silva ED, Cunha L, Sousa L (2014) Risk of multiple sclerosis after optic neuritis in patients with normal baseline brain MRI. J Clin Neurosci 21: 583-586.

46. Toosy AT, Mason DF, Miller DH (2014) Optic neuritis. Lancet Neurol 13: 83-99.

47. Klistorner A, Arvind H, Nguyen T, Garrick R, Paine M, et al. (2008) Axonal loss and myelin in early ON loss in postacute optic neuritis. Ann Neurol 64: 325-331.

48. Costello F, Coupland S, Hodge W, Lorello GR, Koroluk J, et al. (2006) Quantifying axonal loss after optic neuritis with optical coherence tomography. Ann Neurol 59: 963-969.

49. de Seze J, Blanc F, Jeanjean L, Zéphir H, Labauge P, et al. (2008) Optical coherence tomography in neuromyelitis optica. Arch Neurol 65: 920-923.
50. Kupersmith MJ, Anderson S, Kardon R (2013) Predictive value of 1 month retinal nerve fiber layer thinning for deficits at 6 months after acute optic neuritis. Mult Scler 19: 1743-1748.

51. Yeh EA, Marrie RA, Reginald YA, Buncic JR, Noguera AE, et al. (2014) Functional-structural correlations in the afferent visual pathway in pediatric demyelination. Neurology 83: 2147-2152.

52. Gabilondo I, Martínez-Lapiscina EH, Martínez-Heras E, Fraga-Pumar E, Llufriu $\mathrm{S}$, et al. (2014) Trans-synaptic axonal degeneration in the visual pathway in multiple sclerosis. Ann Neurol 75: 98-107.

53. Gundogan FC, Demirkaya S, Sobaci G (2007) Is optical coherence tomography really a new biomarker candidate in multiple sclerosis?--A structural and functional evaluation. Invest Ophthalmol Vis Sci 48: 5773-5781.

54. Naismith RT, Tutlam NT, Xu J, Klawiter EC, Shepherd J, et al. (2009) Optica coherence tomography differs in neuromyelitis optica compared with multiple sclerosis. Neurology 72: 1077-1082.

55. Rebolleda G, Muñoz- Negrete FJ. Protocolos en Neuro- oftalmología. Mesa Redonda. Sociedad Española de Oftalmología. Madrid, 2010. P. 31.

56. González-López JJ, Rebolleda G, Leal M, Oblanca N, Muñoz-Negrete FJ, et al. (2014) Comparative diagnostic accuracy of ganglion cell-inner plexiform and retinal nerve fiber layer thickness measures by Cirrus and Spectralis optical coherence tomography in relapsing-remitting multiple sclerosis. Biomed Res Int.

57. Naismith RT, Tutlam NT, Xu J, Shepherd JB, Klawiter EC, et al. (2009) Optica coherence tomography is less sensitive than visual evoked potentials in optic neuritis. Neurology 73: 46-52.

58. Hickman SJ, Toosy AT, Miszkiel KA, Jones SJ, Altmann DR, et al. (2004) Visual recovery following acute optic neuritis-a clinical, electrophysiological and magnetic resonance imaging study. J Neurol 251: 996-1005.

59. Beck RW, Cleary PA, Anderson MM, Keltner JL, Shults WT, et al. (1992) A randomized, controlled trial of corticosteroids in the treatment of acute optic neuritis. The Optic Neuritis Study Group. N Engl J Med 326: 581-588.

60. Gal RL, Vedula SS, Beck R (2012) Corticosteroids for treating optic neuritis Cochrane Database Syst Rev.

61. Sellebjerg F, Nielsen HS, Frederiksen JL, Olesen J (1999) A randomized, controlled trial of oral high-dose methylprednisolone in acute optic neuritis. Neurology 52: 1479-1484.

62. Noseworthy JH, O'Brien PC, Petterson TM (2001) A randomized trial of intravenous immunoglobulin in inflammatory demyelinating optic neuritis. Neurology 56: 1514-1522.

63. Roed HG, Langkilde A, Sellebjerg F, Lauritzen M, Bang P, et al. (2005) A double-blind, randomized trial of IV immunoglobulin treatment in acute optic neuritis. Neurology 64: 804-810.

64. CHAMPS Study Group (2001) Interferon beta-1a for optic neuritis patients at high risk for multiple sclerosis. Am J Ophthalmol 132: 463-471.

65. Comi G, Filippi M, Barkhof F, Durelli L, Edan G, et al. (2001) Effect of early interferon treatment on conversion to definite multiple sclerosis: a randomised study. Lancet 357: 1576-1582.

66. Kappos L, Polman CH, Freedman MS, Edan G, Hartung HP, et al. (2006) Treatment with interferon beta-1b delays conversion to clinically definite and McDonald MS in patients with clinically isolated syndromes. Neurology 67 1242-1249.

67. Comi G, Martinelli V, Rodegher M (2009) Effect of glatiramer acetate on conversion to clinically definite multiple sclerosis in patients with clinically isolated syndrome (PreCISe study): a randomised, double-blind, placebocontrolled trial. Lancet 374: 1503-1511.

68. Rebolleda G, Muñoz- Negrete FJ. Protocolos en Neuro- oftalmología. Mesa Redonda. Sociedad Española de Oftalmología. Madrid, 2010. P. 32.

69. Coles A (2015) Newer therapies for multiple sclerosis. Ann Indian Acad Neuro 18: S30-34.

70. Farris BK, Pickard DJ (1990) Bilateral postinfectious optic neuritis and intravenous steroid therapy in children. Ophthalmology 97: 339-345.

71. Rappoport D, Goldenberg-Cohen N, Luckman J, Leiba H (2014) Parainfectious optic neuritis: manifestations in children vs adults. J Neuroophthalmol 34: 122129 
Citation: Pérez Bartolomé F, García Vasco L, Abreu Ventura N, Arcos Villegas G, Santos Bueso E, et al. (2015) Diagnosis Approach of Optic Neuritis. J Neurol Neurophysiol 6: 345. doi:10.4172/2155-9562.1000345

72. Yu-Wai-Man P, Griffiths PG, Hudson G, Chinnery PF (2009) Inherited mitochondrial optic neuropathies. J Med Genet 46: 145-158.

73. Brown MD, Sun F, Wallace DC (1997) Clustering of Caucasian Leber hereditary optic neuropathy patients containing the 11778 or 14484 mutations on an mtDNA lineage. Am J Hum Genet 60: 381-387.

74. Smith JL, Hoyt WF, Susac JO (1973) Ocular fundus in acute Leber optic neuropathy. Arch Ophthalmol 90: 349-354.

75. Peragallo JH, Newman NJ (2015) Is there treatment for Leber hereditary optic neuropathy? Curr Opin Ophthalmol 26: 450-457.

76. Howell N (2003) LHON and other optic nerve atrophies: the mitochondrial connection. Dev Ophthalmol 37: 94-108.

77. Galetta SL, Cornblath WT (2010) Should most patients with optic neuritis be tested for neuromyelitis optica antibodies and should this affect their treatment? J Neuroophthalmol 30: 376-378.

78. Drori T, Chapman J (2014) Diagnosis and classification of neuromyelitis optica (Devic's syndrome). Autoimmun Rev 13: 531-533.

79. Ghezzi A, Bergamaschi R, Martinelli V, Trojano M, Tola MR, et al. (2004) Clinical characteristics, course and prognosis of relapsing Devic's Neuromyelitis Optica. J Neurol 251: 47-52.

80. Wingerchuk DM, Lennon VA, Lucchinetti CF, Pittock SJ, Weinshenker BG (2007) The spectrum of neuromyelitis optica. Lancet Neurol 6: 805-815.

81. Lim YM, Pyun SY, Lim HT, Jeong IH, Kim KK (2014) First-ever optic neuritis: distinguishing subsequent neuromyelitis optica from multiple sclerosis. Neurol Sci 35: 781-783.

82. Wingerchuk DM, Banwell B, Bennett JL, Cabre P, Carroll W, et al. (2015) International Panel for NMO Diagnosis. International consensus diagnostic criteria for neuromyelitis optica spectrum disorders. Neurology 85: 177-189.

83. Petzold A, Plant GT2 (2014) Diagnosis and classification of autoimmune optic neuropathy. Autoimmun Rev 13: 539-545.

84. Kim SH, Huh SY, Lee SJ, Joung A, Kim HJ (2013) A 5-year follow-up of rituximab treatment in patients with neuromyelitis optica spectrum disorder. JAMA Neurol 70: 1110-1117.

85. Petzold A, Plant GT (2014) Chronic relapsing inflammatory optic neuropathy: a systematic review of 122 cases reported. J Neurol 261: 17-26.
86. Petzold A, Pittock S, Lennon V, Maggiore C, Weinshenker BG, et al. (2010) Neuromyelitis optica-IgG (aquaporin-4) autoantibodies in immune mediated optic neuritis. J Neurol Neurosurg Psychiatry 81: 109-111.

87. Petzold A, Plant GT (2014) Chronic relapsing inflammatory optic neuropathy: a systematic review of 122 cases reported. J Neurol 261: 17-26.

88. Plant GT, Sibtain NA, Thomas D (2011) Hyperacute corticosteroid treatment of optic neuritis at the onset of pain may prevent visual loss: a case series. Mult Scler Int 2011: 815068.

89. Kurne A, Krabudak R, Cakmakli GY (2010) Recurrent optic neuritis: clues from a long-term follow-up study of recurrent and bilateral optic neuritis patients. Eye Brain 2: 15-20.

90. Pandit L, Shetty R, Misri Z, Bhat S, Amin H, et al. (2012) Optic neuritis: experience from a south Indian demyelinating disease registry. Neurol India 60: $470-475$.

91. Gaier ED, Boudreault K, Rizzo JF, et al. (2015) Atypical Optic Neuritis. Curr Neurol Neurosci Rep 15: 76.

92. Cross SA, Salomao DR, Parisi JE, Kryzer TJ, Bradley EA, et al. (2003) Paraneoplastic autoimmune optic neuritis with retinitis defined by CRMP-5-lgG Ann Neurol 54: 38-50.

93. Rahimy E, Sarraf D (2013) Paraneoplastic and non-paraneoplastic retinopathy and optic neuropathy: evaluation and management. Surv Ophthalmol 58: 430458.

94. Sheorajpanday $R$, Slabbynck $H$, Van De Sompel W, Galdermans D, Neetens I, et al. (2006) Small cell lung carcinoma presenting as collapsin response-mediating protein (CRMP) -5 paraneoplastic optic neuropathy. $J$ Neuroophthalmol 26: 168-172.

95. Rebolleda G, Muñoz- Negrete FJ. Protocolos en Neuro- oftalmología. Mesa Redonda. Sociedad Española de Oftalmología. Madrid, 2010. P. 36.

96. Rebolleda G, Muñoz- Negrete FJ. Protocolos en Neuro- oftalmología. Mesa Redonda. Sociedad Española de Oftalmología. Madrid, 2010. P. 78.

97. Currò N, Covelli D, Vannucchi G, Campi I, Pirola G, et al. (2014) Therapeutic outcomes of high-dose intravenous steroids in the treatment of dysthyroid optic neuropathy. Thyroid 24: 897-905.

98. Mikkilä H, Karma A, Viljanen M, Seppälä I (1999) The laboratory diagnosis of ocular Lyme borreliosis. Graefes Arch Clin Exp Ophthalmol 237: 225-230. 